\title{
Correction to: The Relative and Interactive Effects of Actual and Perceived Gambling Exposure on Gambling Behaviour
}

\author{
S. M. Ofori Dei ${ }^{1}$ - D. R. Christensen ${ }^{1,4}$ (D) O. A. Awosoga ${ }^{1}$ B. K. Lee ${ }^{1} \cdot$ A. C. Jackson ${ }^{2,3,4,5}$ \\ Published online: 5 April 2021 \\ (c) Springer Science+Business Media, LLC, part of Springer Nature 2021
}

\section{Correction to: Journal of Gambling Studies https://doi.org/10.1007/s10899-020-09991-w}

The original version of this article contained an error in the reference section. The following reference "Corp, Stata. (2019). Stata statistical software: Release 16. College Station, TX: StataCorp LLC." should read as "StataCorp. (2019). Stata statistical software: Release 16. College Station, TX: StataCorp LLC.”. The original article has been corrected.

Publisher's Note Springer Nature remains neutral with regard to jurisdictional claims in published maps and institutional affiliations.

The original article can be found online at https://doi.org/10.1007/s10899-020-09991-w.

D. R. Christensen

darren.christensen@uleth.ca

1 Faculty of Health Sciences, University of Lethbridge, 4401 University Drive, Lethbridge, AB T1K 3M4, Canada

2 Australian Centre for Heart Health, North Melbourne, Australia

3 Faculty of Health, Deakin University, Melbourne, Australia

4 Melbourne Graduate School of Education, University of Melbourne, Parkville, Australia

5 Centre on Behavioural Health, University of Hong Kong, Pok Fu Lam, Hong Kong 